\title{
TRANSLATION OF THE TRAVEL WEB PORTAL TEXT CONTENT AS A WAY TO GLOBALIZE REGION BRAND ${ }^{1}$
}

\author{
Anna A. Gureeva \\ Volgograd State University, Volgograd, Russia \\ Anna A. Novozhilova \\ Volgograd State University, Volgograd, Russia \\ Tatiana S. Sidorovich \\ Volgograd State University, Volgograd, Russia
}

\begin{abstract}
The article presents an analysis of the translation of the Volgograd and Volgograd region travel web portal from Russian into English and German within the aspect of the globalization process and promotion of the region brand. The authors concentrate their attention on the origin of functionally equivalent translation directed toward the linguo-cultural and pragmatic adaptation of the source tourist texts for a global recipient. The paper reveals that the translator is to choose a comprehensive strategy to create a globalized version of the travel web portal, that is to preserve the optimal amount of general information, eliminate information irrelevant for the global recipient, minimize the loss of the key information important from the pragmatic perspective of creating a globalised version of the target text, and, if appropriate, add more detailed or explanatory information which can better provide obtaining of the information about foreign culture and history by a foreign recepient.

The efficient translation of the text content of the travel web portal aimed at a "global recipient" is achieved and provided by translation technologies chosen by the translator in accordance with the discourse determined strategies. Such technologies create functionally equivalent translation opportunity: the source text is adapted for a "global recipient" by considering culturally important and pragmatically adequate situation context.

Key words: translation, travel discourse, globalization, region brand, functionally equivalent translation, translation method, linguo-cultural adaptation, pragmatic adaptation, global recipient.

Citation. Gureeva A.A., Novozhilova A.A., Sidorovich T.S. Translation of the Travel Web Portal Text Content as a Way to Globalize Region Brand. Vestnik Volgogradskogo gosudarstvennogo universiteta. Seriya 2, Yazykoznanie [Science Journal of Volgograd State University. Linguistics], 2017, vol. 16, no. 4, pp. 150-157. (in Russian). DOI: https://doi.org/10.15688/jvolsu2.2017.4.13

\section{ПЕРЕВОД ТЕКСТОВОГО КОНТЕНТА ТУРИСТИЧЕСКОГО ПОРТАЛА КАК СПОСОБ ГЛОБАЛИЗАЦИИ БРЕНДА РЕГИОНА ${ }^{1}$}

\author{
Анна Андреевна Гуреева \\ Волгоградский государственный университет, г. Волгоград, Россия \\ Анна Алексеевна Новожилова \\ Волгоградский государственный университет, г. Волгоград, Россия \\ Татьяна Станиславовна Сидорович \\ Волгоградский государственный университет, г. Волгоград, Россия
}


Аннотация. В статье представлен анализ перевода туристического портала Волгограда и Волгоградской области с русского языка на английский и немецкий языки с точки зрения глобализации и популяризации бренда региона. В результате был выделен ряд принципов создания функционально-эквивалентного перевода, направленных на лингвокультурную и прагматическую адаптацию исходных туристических текстов, ориентированных на глобального получателя. Доказано, что в целях создания глобализованной версии переводчик должен руководствоваться следующими основными стратегиями: стремление к сохранению оптимального объема общей информации (элиминация избыточных или нерелевантных для глобального получателя сведений, минимизация потерь ключевой информации важной с точки зрения прагматики создания глобализованной версии текста), а также, в случае необходимости, добавление уточняющих данных, облегчающих восприятие иностранным адресатом чужой истории и культуры.

Достижение эффективности перевода контента туристического интернет-портала, ориентированного на «глобального получателя», обеспечивается за счет переводческих технологий, избранных переводчиком в соответствии с дискурсивно-обусловленными стратегиями. Благодаря использованию таких технологий создается функционально-эквивалентный перевод: происходит адаптация исходного текста с учетом культурно-значимого и прагматически адекватного ситуативного контекста.

Ключевые слова: перевод, туристический дискурс, глобализация, бренд региона, функциональноэквивалентный перевод, переводческий прием, лингвокультурная адаптация, прагматическая адаптация, глобальный получатель.

Цитирование. Гуреева А. А., Новожилова А. А., Сидорович Т. С. Перевод текстового контента туристического портала как способ глобализации бренда региона // Вестник Волгоградского государственного университета. Серия 2, Языкознание. - 2017. - T. 16, № 4. - C. 150-157. - DOI: https://doi.org/10.15688/jvolsu2.2017.4.13

1

В настоящее время в результате глобализации в мире стремительно развивается туристическая отрасль. Туризм становится необходимой и востребованной составляющей современного социума. В.А. Митягина утверждает, что туризм как феномен цивилизации, являясь современной массовой формой организации путешествий, реализует потребности личности, связанные с диверсификацией возможностей и компетенций, и свидетельствует о динамике социокультурного развития: росте свободного времени, изменении ценностных ориентиров, улучшении качества жизни [Митягина, 2016, с. 9-10]. Э.Ю. Новикова подчеркивает, что туризм влияет на укрепление межличностного и межкультурного взаимодействия и расширяет границы познания [Новикова, 2016a, с. 78]. Туризм можно считать одной из форм реализации социальной активности индивида, желание и потребность которого в обогащении собственного культуро- и страноведческого опыта сегодня в значительной степени стимулированы активным вниманием современных СМИ к туризму как увлекательному и полезному способу отдыха / развлечения / времяпрепровождения [Гуреева, 2016, с. 23]. Следовательно, туристическая сфера не только является важным факто- ром развития экономики, но и представляет собой широкое поле для саморазвития индивидов и реализации их личных стремлений.

На фоне этих тенденций заметно возросла популярность международного туризма. С.А. Королькова и А.П. Наумова отмечают, что «все больше и больше людей стремятся выехать за пределы своей страны, чтобы посетить различные достопримечательности и другие государства. Жажда к перемене мест и новым впечатлениям, растиражированным в глобальных массмедиа, способствует росту мобильности жителей планеты» [Королькова, Наумова, 2016, с. 104]. Международный туризм является одной из крупнейших и динамично развивающихся отраслей современной индустрии и, безусловно, стал «одним из проявлений готовности этносоциумов не только к диалогу и интеграции, но и к глобализации, потому что в туристической деятельности находит выражение одобрение сосуществования культур в индивидуальном опыте» [Митягина, 2009, с. 88]. Глобальность туристских практик и интернет-коммуникации детерминирует поиск интеграционных механизмов осуществления англоязычной туристической интернет-коммуникации в контексте глобализации [Ромадина, 2016, с. 155]. По мнению Э.Ю. Новиковой, глобализация, с одной стороны, способствует унификации глобальной 
коммуникации в целом и культурного туризма в частности, с другой - укреплению локальной идентичности регионов, сохранению исторической памяти и наследия [Новикова, 2016б, с. 155]. Вследствие этого появилась необходимость осуществления межкультурной коммуникации в индустрии международного туризма, что, в свою очередь, стало стимулом к созданию сопровождающих эту деятельность текстов рекламного и информативносправочного характера и не могло не привлечь внимания филологов и специалистов в области рекламы [Филатова, 2012, с. 56].

Туристический дискурс уже давно стал объектом лингвистических и лингвокультурологических исследований. В последнее время фокус интересов лингвистов, занимающихся изучением туристического дискурса, сместился к анализу имиджевых текстов и текстов, направленных на территориальное брендирование, так как его грамотное лингвистическое сопровождение является важным компонентом, способствующим повышению аттрактивности отдельных регионов и привлечению в них большего количества туристов. Исследователи отмечают, что создание текстов брендинга сферы туризма является комплексной задачей, и, подчеркивая их несомненную важность, выделяют в маркетинговой прагматике таких текстов следующие составляющие:

- привлечение туристских потоков и повышение доходов казны города / региона;

- привлечение внимания инвесторов и повышение притока инвестиций;

- увеличение влияние города как внутри страны, так и за ее пределами;

- построение партнерских отношений с частными организациями / частными лицами, другими городами и т. д. [Гуреева, 2017, с. 129].

Как показано Т.Ю. Махортовой, маркетинговый подход к брендингу хотя и является доминирующим, но он не может быть эффективным без лингвистических методов исследования, поскольку вербальная составляющая играет ключевую роль в формировании туристически привлекательного образа страны / региона / города [Махортова, 2017, с. 142].

Современным средством получения информации при планировании и самостоятельной организации туристической поездки в тот или иной город, особенно зарубежный, можно считать туристические интернет-ресурсы.

\section{2}

Повышение интереса к региону, увеличение турпотока и, как следствие, получение туристской отраслью дополнительных инвестиций напрямую зависит от того, как представлен город в информационных туристических Интернет-ресурсах и какие объекты туристского значения предложены вниманию потенциального туриста (см. об этом: [Гуреева, 2016, c. 30]. Наиболее востребованными источниками информации среди туристов, планирующих свое путешествие в определенном регионе, являются туристические порталы. Они размещаются в интернете, и к их главным достоинствам относится общедоступность и информативность. Туристический интернет-портал города, который создает определенное социокультурное пространство и сочетает в себе признаки и элементы различных институциональных дискурсов: медийного, виртуального, административного, туристического, маркетингового, культурного и др., - это мощный инструмент для привлечения внимания широкого круга потенциальных потребителей и формирования образа глобально-ориентированного города, то есть так называемого «глокального» города и территориального брендинга в целом [Новикова, 2016б, с. 155]; это важный элемент продвижения туристского потенциала региона и средство создания культурно значимых социокоммуникативных контекстов, аккумулирующих на своих страницах от краткой до максимально детальной и понятной информации о наиболее интересных достопримечательностях [Новикова, 2015, с. 53].

Многие туристические порталы имеют многоязычные версии, что способствует привлечению внимания большего количества потенциальных туристов из-за рубежа. Следовательно, анализ качества перевода имиджевых текстов в сфере туризма и выявление успешных переводческих технологий относится к приоритетным задачам современных лингвистов, их решение будет способствовать формированию благоприятного образа региона.

При создании глобализованного туристического гипертекста необходимо учиты- 
вать не только прагматические особенности, влияющие на процесс перевода, но и осуществлять перевод в соответствии с принципом передачи «оптимальной степени полноты текста», которую Е.В. Белоглазова определяет как семантику, достаточную для однозначного опознания когнитивных моделей, на основе которых выстраивается правильная интерпретация текста [Белоглазова, 2010, с. 29].

Задача сохранения достаточного объема общей информации для реализации коммуникативных целей участников дискурса, несмотря на лингвокультурные и индивидуальные различия адресатов, может быть решена с помощью использования макроправил, в частности опущения и обобщения (генерализации), позволяющих вывести глобальное значение эпизода из значений его предложений [Дейк, 1989, с. 42-43]. Опущение предполагает отбрасывание информации, нерелевантной для глобального значения текста; генерализация заключается в обобщении ряда пропозиций.

Перевод материалов туристического портала с одного языка на другой предполагает значительные расхождения на вне- и внутритекстовом уровнях для достижения максимального соответствия ожиданиям потенциальных реципиентов. Это означает, что близость оригиналу может стать стратегической ошибкой при переводе. Следовательно, для достижения функциональной и прагматической адекватности важно сохранить эстетику текста с точки зрения целевой культуры, а не текста оригинала.

3

Возможности применения приемов глобализации контента в соответствии с вышеизложенными принципами рассмотрим на примере перевода с русского языка на английский и немецкий материалов туристического интернет-портала Волгограда и Волгоградской области «Волгоградский край: территория путешествий».

3.1. При переводе русскоязычных текстов, размещенных на портале, на английский язык, как правило, используются опущение избыточной информации и генерализация.
(1) Оригинал: В нескольких десятках километров к западу от озера Эльтон располагается небольшое горько-соленое озеро Булухта, что с калмыцкого языка можно перевести как «родниковое».

Перевод: Small bitter salty lake Bulukhta is situated in Pallasovsky district of the Volgograd region between the Volga river and lake Elton.

Ключевая информация данного фрагмента - сведения о местоположении озера Булухта. Однако его расположение описывается относительно другого, предположительно более известного для русскоязычного получателя географического объекта - озера Эльтон (в нескольких десятках километров к западу от озера Эльтон). Представляется, что данное описание малоинформативно для «глобального» получателя, поэтому вполне объяснимо предпринятое в переводе изменение такого описания расположения туристического объекта. Опущенная информация компенсируется описанием местоположения в координатах более «крупной» географической реалии in Pallasovsky district of the Volgograd region, а также добавлением географической привязки к всемирно известной русской реке Волге. По причине малой значимости для «глобального» получателя редукции подвергается и информация об этимологии названия озера (что с калмыцкого языка можно перевести как «родниковое»).

(2) Оригинал: Гости празднества имеют возможность погрузиться в водоворот собьтий противоречивого и жестокого столетия, увидеть Ивана Грозного, Лжедмитрия II, государевых стрельияов, вольных казаков и европейских наемников.

Перевод: Guests of the festival have an opportunity to plunge into the atmosphere of the $16^{\text {th }}$ century, controversial and cruel period of Russia's history, and meet famous historical personalities.

В данном фрагменте рекламируется международный фестиваль военно-исторической реконструкции «Казачья застава» в Даниловском районе Волгоградской области. Описание исторического периода, реконструируемого во время фестиваля, ориентировано на представителя «своей» культуры и может вызвать некоторый когнитивный диссонанс у представителей «чужой» культуры (противо- 
речивое и жестокое столетие). Поэтому оправдано при переводе добавление хрононима (the $16^{\text {th }}$ century). Кроме того, в приведенном фрагменте текста содержится информация об исторических персоналиях, возможно неизвестных «глобальному» получателю (Иван Грозный, Лжедмитрий II, государевы стрельцы, вольные казаки и европейские наемники). В переводе эта информация подвергается генерализации и заменяется на обобщение (famous historical personalities). Таким образом, при переводе происходит культурно-прагматическая адаптация ключевой информации и опущение второстепенной.

Следующий фрагмент описывает арбузный фестиваль, который ежегодно проводится в городе Камышине Волгоградской области:

(3) Оригинал: По всему городу открываются «арбузные обжорки»- прототипь старинных арбузных лавок, где можно «съесть арбузов от пуза», столько, сколько влезет. Но на скорость кто больше!

Перевод: During the festival the town is full of watermelon small shops where guests can try watermelons and take part in watermelon speed eating.

Представленный фрагмент изобилует культурно-исторической информацией. Текст перевода уменьшился в объеме за счет культурной адаптации основной информации и опущения второстепенной (с точки зрения представителя другой культуры - избыточной). Несмотря на то что при переводе опущен фразеологизм (съесть арбузов от пуза) и описание особенностей самого процесса съедания арбузов (Но на скорость - кто больше!), полученный англоязычный текст является прагматически адаптированным и ориентированным на глобального получателя.

Следует заметить, что во всех приведенных примерах текст перевода уменьшился в объеме по сравнению с текстом оригинала за счет культурной адаптации основной информации и опущения второстепенной или избыточной с точки зрения «чужой» культуры.

3.2. При анализе перевода материала туристического интернет-портала «Волгоградский край: территория путешествий» на немецкий язык, как в переводах на английский, обнаруживаются расхождения с оригиналом, обусловленные применением приемов опущения и генерализации.

(4) Оригинал: Отправивщись от площзади Павших борияов направо по улице Мира в сторону планетария, можно дойти до городской библиотеки имени Горького, полюбоваться тихими улочками и старинными домами, отдохнуть в сквере.

Перевод: Vom Platz der Gefallenen Kämpfer kann man nach rechts gehen, die Uliza Mira mit ihren eleganten cremefarbenen Wohnhäusern und ruhigen Innenhöfen entlang. Nach einer Unterführung sehen wir linkerhand ein modernes, kastenförmiges weißes Gebäude: die Gorki-Bibliothek.

В этом фрагменте переводчик опускает упоминание одного из объектов, указывающих направление маршрута (в сторону планетария), оставляя другие ориентиры (от площади Павших бориов направо по уличе Мира), а также добавляет топографическую привязку подземный переход (Nach einer Unterführung). Для иноязычного получателя при движении по описываемому маршруту такое описание представляется более понятным и информативным, поскольку планетарий не виден с площади Павших борцов, и многие иностранцы могуг незнать, в какой стороне находится данный туристический объект. Кроме того, добавление информации о промежуточном ориентире - подземном переходе, через который необходимо пройти, поможет им двигаться вперед, пребывая в уверенности, что они не сбились с пути. В тексте перевода изменено описание здания библиотеки: словосочетание городская библиотека, которое может оказаться для иностранца малоинформативным, заменено на более подробное ein modernes, kastenförmiges weißes Gebäude: die Gorki-Bibliothek (современное коробчатое белое здание библиотеки). Помимо этого, добавлено указание на расположение здания относительно движущегося туриста - linkerhand (слева), что позволяет безошибочно определить, о каком именно объекте идет речь. Использование описанных переводческих приемов представляется оправданным, поскольку сохраняется и не искажается семантика текста оригинала, а также создается возможность лучшей ориентации иноязычного адресата на описываемом маршруте.

Рассмотрим еще один пример перевода фрагмента туристического текста с рус- 
ского языка на немецкий, наглядно показывающий стремление переводчика к созданию более глобализованной по сравнению с оригиналом версии.

(5) Оригинал: В супермаркете Бабы-Яги можно увидеть волшебное зеркальце, отвечающее на все вопросы с помощью интернета, сапоги-скороходы с противоугонным устройством, ковер-самолет, протертый стариком Хоттабычем, скатерть-самобранку, шапку-невидимку, гусли-самогуды, сапоги-скороходы и много других сказочных атрибутов.

Перевод: Im Museum selbst finden sich alle möglichen Zaubergegenstände aus der Märchenwelt und der Besucher kann sich selbst in einen richtigen Magier verwandeln, eine Möglichkeit, die man auf keinen Fall verpassen sollte.

На немецком языке информация передана в более сжатом виде, чем она представлена в тексте оригинала. В переводе не предпринималась попытка передать каким-либо образом наименования всех перечисляемых в оригинале сказочных устройств (сапоги-скороходы, ковер-самолет, скатерть-самобранка, шапка-невидимка, гусли-самогуды и т. д.). Переводчик применил прием генерализации и обобщил эти наименования как alle möglichen Zaubergegenstände aus der Märchenwelt (всевозможные волшебные предметы сказочного мира). Такая культурно-прагматическая адаптация представляется необходимой, поскольку многие из упомянутых волшебных атрибутов являются типичными для русских сказок, и, несмотря на то что похожие предметы существуют и в немецкоязычных сказках, они часто отличаются по своим характеристикам, следовательно, перевод таких наименований посредством немецкоязычных эквивалентов не может передать всего колорита русских сказок и был бы не адекватным. Прием генерализации использован также в начале фрагмента, где переводчик не стал переводить дословно словосочетание $B$ cynepмаркете Бабы-Яги, а передал это обстоятельство места при помощи словосочетания Im Museum (в музеe), не уточняя местонахождения сказочных предметов на территории музея, поскольку Баба-Яга также является персонажем исключительно русских сказок и для многих иностранных адресатов, не знако- мых с такими сказками, транслитерация ее имени и/или описательный перевод были бы непонятными и избыточными.

\section{4}

Проанализированные примеры наглядно иллюстрируют тот факт, что переводчики как при работе с англоязычной, так и с немецкоязычной версиями стремились к элиминации избыточных сведений и к минимизации потерь важной информации, при необходимости внося уточняющие, объясняющие дополнения, релевантные для потенциальных зарубежных туристов.

Таким образом, эффективность перевода контента туристического интернет-портала, ориентированного на «глобального получателя», достигается в результате использования переводческих технологий, соответствующих дискурсивно-обусловленным стратегиям и позволяющих адаптировать исходный текст с учетом культурно-значимого и прагматически адекватного ситуативного контекста, то есть в результате создания функционально-эквивалентного перевода. Грамотно выполненные переводы материалов многоязычных туристических порталов способствуют популяризации российского туризма и развитию регионального брендирования.

\section{ПРИМЕЧАНИЕ}

${ }^{1}$ Исследование выполнено при финансовой поддержке Российского фонда фундаментальных исследований (РФФИ) и Администрации Волгоградской области, проект № 17-14-34001 «Региональный туризм как фактор формирования дискурса и технологии перевода: номинативные и коммуникативно-прагматические конвенции текстов брендинга» (Региональный конкурс «Волжские земли в истории и культуре России» 2017 - Волгоградская область).

\section{СПИСОК ЛИТЕРАТУРЫ}

Белоглазова Е. В., 2010. Дискурсность, интердискурсность, полидискурсность литературы для детей. СПб. : Изд-во СПбГУЭФ. 195 с.

Гуреева А. А., 2016. Информационный туристический интернет-ресурс о городе (на примере 
г. Волгограда) // Homo Loquens: Вопросы лингвистики и транслятологии : Сб. ст. / В. А. Митягина (отв. ред). Волгоград : Изд-во ВолГУ. Вып. 9. С. 22-31.

Гуреева А. А., 2017. PR-функция текста туристического брендинга: лингвистические средства как способ реализации // Брендинг как коммуникативная технология XXI века. Материалы III Всероссийской научно-практической конференции (Санкт-Петербург, 1-3 марта 2017 г.). СПб. : Санкт-Петербургский государственный экономический университет. C. $128-131$.

Дейк Т. А. ван, 1989. Язык. Познание. Коммуникация / пер. с англ.; сост. В. В. Петрова; под ред. В. И. Герасимова; вступ. ст. Ю. Н. Караулова и В. В. Петрова. М. : Прогресс. 312 с.

Королькова С. А., Наумова А. П., 2016. Перевод путеводителя: сложности культурного трансфеpa // Лингвистическая и транслатологическая логистика многоязычного туристического интернет-ресурса : коллективная монография под общ. ред. В. А. Митягиной. Волгоград : Изд-во ВолГУ. С. 104-130.

Махортова Т. Ю., 2017. Лингвистические аспекты изучения туристического брендинга // Брендинг как коммуникативная технология XXI века материалы III Всероссийской научно-практической конференции (Санкт-Петербург, 13 марта 2017 г). СПб. : Санкт-Петербургский государственный экономический университет. С. 141-144.

Митягина В. А., 2009. Коммуникативные действия в туристическом дискурсе // Иностранные языки в высшей школе. Вып. 4 (11). С. 88-97.

Митягина В. А., 2016. Логистика многоязычного туристического дискурса: межкультурный дискурс в координатах глобализации // Лингвистическая и транслатологическая логистика многоязычного туристического интернет-ресурса : коллективная монография / под общ. ред. В. А. Митягиной. Волгоград : Изд-во ВолГУ. С. 9-24.

Новикова Э. Ю., 2015. Туристический имидж глокального города: лингвопрагматическое измерение // Вестник Воронежского государственного университета. Серия: Лингвистика и межкультурная коммуникация. № 1. С. 53-57.

Новикова Э. Ю., 2016а. Лингвопрагматические характеристики интернет-дискурса медицинского туризма // Вестник Волгоградского государственного университета. Серия 2: Языкознание. 2016. Т. 15, № 3. С. 78-86. DOI: https:// doi.org/10.15688/jvolsu2.2016.3.8.

Новикова Э. Ю., 2016б. Коммуникативно-прагматическая парадигма перевода в межкультур- ном туристическом дискурсе // Лингвистическая и транслатологическая логистика многоязычного туристического интернет-ресурса : коллективная монография / под общ. ред. проф. В. А. Митягиной. Волгоград : Изд-во ВолГУ. С. 153-173.

Ромадина И. Д., 2016. Глобализация контента международного туристического сайта как задача перевода (на материале англоязычных сайтов) // Филологические науки. Вопросы теории и практики. № 9 (63), ч. 1. С. 154-159.

Филатова Н. В., 2012. Стратегии самопрезентации субъекта туристического дискурса // Вестник Московского государственного лингвистического университета. Серия «Гуманитарные науки». Вып. 22 (655). С. 56-67.

\section{ИСТОЧНИКИ}

Многоязычный туристический интернет-портал города Волгограда и Волгоградской области «Волгоградский край - территория путешествий». URL: http://volga-land.volsu.ru.

\section{REFERENCES}

Beloglazova E.V., 2010. Discoursivity, interdiscoursivity, polydiscoursivity of children's books: monograph. Saint Petersburg, SPbGUEF Publ. 195 p. (in Russian).

Gureeva A.A., 2016. Travel Internet resource about a city (the case of Volgograd). Mityagina V.A., ed. Homo Loquens: Voprosy lingvistiki $i$ translyatologii: Sb. st. Volgograd, Izd-vo VolGU, iss. 9, pp. 22-31. (in Russian).

Gureeva A.A., 2017. Branding PR-function in travel discourse texts: ways to perform. Brending kak kommunikativnaya tekhnologiya XXI veka. Materialy III Vserossiyskoy nauchnoprakticheskoy konferentsii, Saint-Petersburg, 1-3 March. Saint Petersburg, Saint Petersburg State University of Economics Publ., pp. 128131. (in Russian).

Dejk T.A. van, 1989. Language. Knowledge. Communication. Moscow, Progress Publ. 312 p. (in Russian).

Korolkova S.A., Naumova A.P., 2016. Translation of a travelguide: difficulties in cultural transfer. Mityagina V.A., ed. Lingvisticheskaya i translatologicheskaya logistika mnogoyazychnogo turisticheskogo internet-resursa.. Volgograd, Izd-vo VolGU Publ., pp. 104-130. (in Russian).

Makhortova T.Yu., 2017. Linguistic aspects of tourist branding's study. Brending kak kommunikativnaya 
tekhnologiya XXI veka. Materialy III Vserossiyskoy nauchno-prakticheskoy konferentsii, Saint-Petersburg, 1-3 March. Saint Petersburg, Saint Petersburg State University of Economics, pp. 141-144. (in Russian).

Mityagina V.A., 2009. Communicative actions in the tourism discourse. Inostrannye yazyki v vysshey shkole [Foreign Languages in Tertiary Education], no. 4, pp. 88-97. (in Russian).

Mityagina V.A., 2016. The logistics of multilingual tourist discourse: intercultural discourse in the context of globalization. Mityagina V.A., ed. Lingvisticheskaya i translatologicheskaya logistika mnogoyazychnogo turisticheskogo internet-resursa. Volgograd, Izd-vo VolGU Publ., pp. 9-24. (in Russian).

Novikova E.Yu., 2015. Tourist image of the "glocal" city: linguistic and pragmatic dimensions. Vestnik Voronezhskogo gosudarstvennogo universiteta. Seriya: Lingvistika $i$ mezhkulturnya kommunikatsiya [Proceedings of Voronezh State University. Linguistics and Intercultural Communication], no. 1, pp. 53-57. (in Russian).

Novikova E.Yu., 2016a. Linguo-pragmatic features of the medical tourism Internet discourse. Vestnik Volgogradskogo gosudarstvennogo universiteta. Seriya 2, Yazykoznanie [Science Journal of Volgograd State University.
Linguistics], vol. 15, no. 3, pp. 78-86. DOI: https:// doi.org/10.15688/jvolsu2.2016.3.8. (in Russian).

Novikova E.Yu., 2016b Communicative and pragmatic paradigm of translation in intercultural travel discourse. Mityagina V.A., ed. Lingvisticheskaya i translatologicheskaya logistika mnogoyazychnogo turisticheskogo internet-resursa. Volgograd, Izd-vo VolGU Publ., pp. 153-173. (in Russian).

Romadina I.D., 2016. Globalization of content of the international tourism website as a target of translation (English-language websites case study). Filologicheskie nauki. Voprosy teorii i praktiki [Philological Sciences. Issues of Theory and Practice], no. 9 (63), vol. 1, pp. 154159. (in Russian).

Filatova N.V., 2012. Subject self-presentation strategies of tourism discourse. Vestnik Moskovskogo gosudarstvennogo lingvisticheskogo universiteta. Seriya "Gumanitarnye nauki" [Vestnik MGLU. The Humanities], no. 22 (655), pp. 56-67. (in Russian).

\section{SOURCES}

Multilingual tourist Internet portal of Volgograd and the Volgograd region "The Volgograd region travel territory". URL: http://volga-land.volsu.ru.

\section{Information about the Authors}

Anna A. Gureeva, Candidate of Sciences (Philology), Assistant Professor, Department of Translation Theory and Practice, Volgograd State University, Prosp. Universitetsky, 100, 400062 Volgograd, Russia, tipp@volsu.ru, http://orcid.org/0000-0002-5993-8138

Anna A. Novozhilova, Candidate of Sciences (Philology), Associate Professor, Department of Translation Theory and Practice, Volgograd State University, Prosp. Universitetsky, 100, 400062 Volgograd, Russia, tipp@volsu.ru, http://orcid.org/0000-0001-7601-9048

Tatyana S. Sidorovich, Candidate of Sciences (Philology), Associate Professor, Department of Translation Theory and Practice, Volgograd State University, Prosp. Universitetsky, 100, 400062 Volgograd, Russia, tipp@volsu.ru, http://orcid.org/0000-0002-1905-4258

\section{Информация об авторах}

Анна Андреевна Гуреева, кандидат филологических наук, старший преподаватель кафедры теории и практики перевода, Волгоградский государственный университет, просп. Университетский, 100, 400062 г. Волгоград, Россия, tipp@volsu.ru, http://orcid.org/0000-0002-5993-8138

Анна Алексеевна Новожилова, кандидат филологических наук, доцент кафедры теории и практики перевода, Волгоградский государственный университет, просп. Университетский, 100, 400062 г. Волгоград, Россия, tipp@volsu.ru, http://orcid.org/0000-0001-7601-9048

Татьяна Станиславовна Сидорович, кандидат филологических наук, доцент кафедры теории и практики перевода, Волгоградский государственный университет, просп. Университетский, 100, 400062 г. Волгоград, Россия, tipp@volsu.ru, http://orcid.org/0000-0002-1905-4258 